\title{
Factors Associated with Pediculosis Capitis among Primary School Children in Kuantan, Pahang
}

Siti Nur Madihah Che Rozela, Nor Faiza Mohd Tohit, Razman Mohd Rus

Kulliyah of Medicine, International Islamic University Malaysia

Introduction: Pediculosis capitis among primary school children is a worldwide problem which carries significant consequences among the school children and caregivers. Despite causing significant health problem which needs to be intervened, only few studies were conducted in Malaysia and there is no previous study conducted in Pahang. Thus, this study aims to investigate the determinants of prevalence of Pediculosis capitis among primary school children in Kuantan, Pahang, Malaysia. Materials and method: An analytical cross-sectional study using cluster random sampling of primary schools was carried out in Kuantan. Selfadministered validated questionnaire was used followed by hair and scalp examination. Multivariate logistics was done to determine the predictors and to control for confounding effect. Results: The overall median age of the 1,365 respondents was 8.0 years. Majority of them were males (53.41\%), Malays $(60.29 \%)$, household income between RM1000-RM2999 (31.87\%) and from urban school location (98.68\%). The overall prevalence of Pediculosis capitis was 9.6\% $(n=131)$. Multivariate logistic regression analysis showed that female (Odds ratio $(O R)=8.571$, 95\% Confidence interval $(\mathrm{Cl})=5.024-14.620)$, Indian $(\mathrm{OR}=5.560,95 \% \mathrm{Cl}=3.384-$ 9.136), those who had number of siblings more than five $(\mathrm{OR}=2.644,95 \% \mathrm{Cl}=1.044$ 6.700), history of contact with infested person (OR=2.445, 95\% Cl=1.619-3.691) and urban school location $(\mathrm{OR}=0.030,95 \% \mathrm{Cl}=0.284-0.091)$ were predictors for Pediculosis capitis. Conclusion: The prevalence of Pediculosis capitis among primary school children in Kuantan, Pahang is endemic(9.6\%) and predictors are female, Indian, having siblings of more than 5 and contact with infested person. Hence, preventive measures are necessary to reduce the transmission of head lice among school children. 